\title{
Ocular TASER Probe Injury Managed with Primary Evisceration: Case Report
}

\author{
Anna B. Sharabura Joseph W. Fong John D. Pemberton \\ Department of Ophthalmology, Jones Eye Institute, University of Arkansas for Medical \\ Sciences (UAMS), Little Rock, AR, USA
}

\section{Keywords}

Thomas A Swift's Electric Rifle probe injury · Globe trauma · Evisceration surgery ·

Sympathetic ophthalmia

\begin{abstract}
A 34-year-old male presented to the emergency department with a penetrating injury of the left globe and orbit from a Thomas A Swift's Electric Rifle (TASER ${ }^{\circledR}$ ) probe. The severity of the globe injury precluded primary closure of the globe; a primary evisceration was performed. In this article, we discuss not only the case in detail but also the TASER ${ }^{\circledR}$ rifle and the literature to support our decision in performing an evisceration rather than an enucleation, which historically has been taught to decrease the risk of sympathetic ophthalmia (SO) in the fellow eye. We are of the opinion, after reviewing the literature, that SO is not an overwhelming reason to choose enucleation over evisceration and that evisceration has an advantage over enucleation with regard to functional and cosmetic outcomes.
\end{abstract}

\section{Introduction}

Thomas A Swift's Electric Rifle (TASER ${ }^{\circledR}$ ) is described as a less-than-lethal weapon designed to incapacitate the target by delivering pulses of electrical shock that cause tonicclonic contractions of the skeletal muscle. This electrical shock is delivered by 9-13-mm-long barbed metal darts, depending on the weapon model, which are fired at $160 \mathrm{ft} / \mathrm{s}$ with pressurized gas and penetrate into skin or clothing to transmit multiple sequential pulses over a

Anna B. Sharabura and Joseph W. Fong equally contributed as first authors.

\section{Karger!}




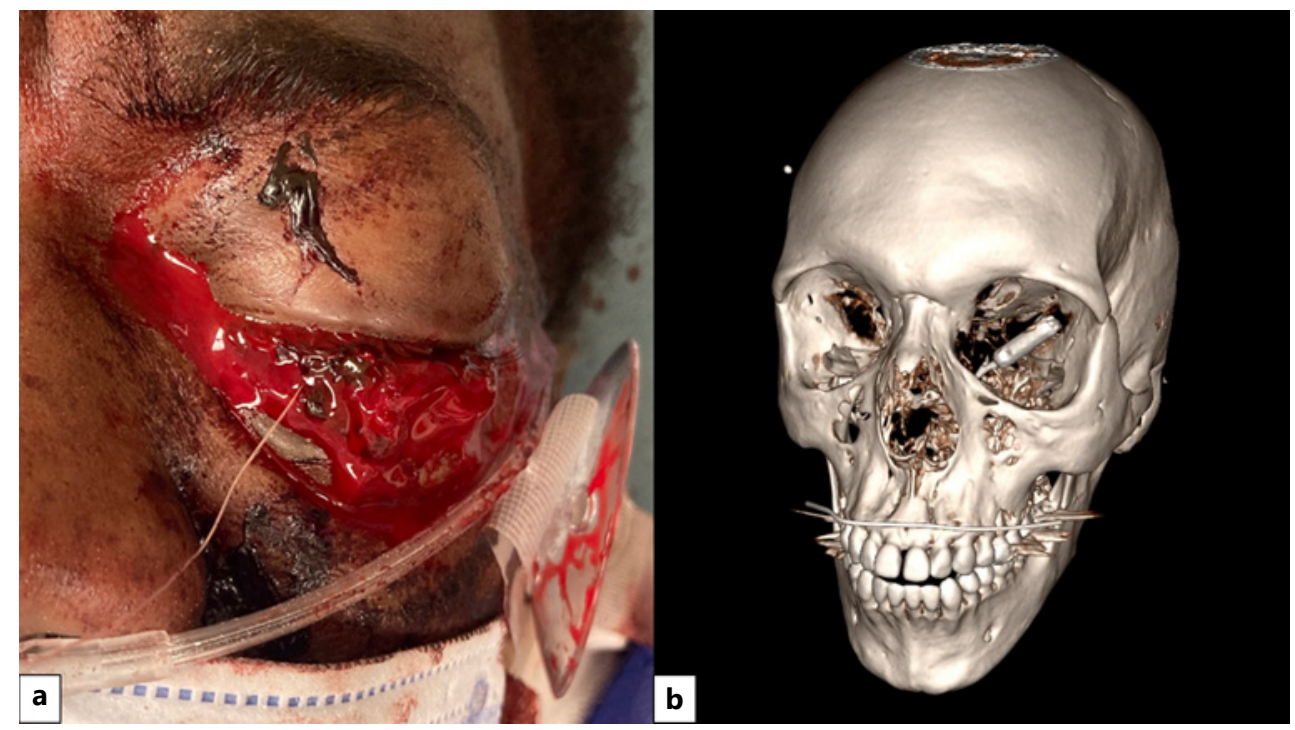

Fig. 1. Clinical photograph showing the impaled probe with TASER wire. a Significant proptosis and prolapse of charred, coagulated uveal tissue resulted from electrical discharge of the TASER weapon. $\mathbf{b}$ CT scan of the orbit demonstrating the cylindrical metallic foreign body perforating the left globe and impaled into the left medial wall of the orbit. TASER, Thomas A Swift's Electric Rifle; CT, computed tomography.

5 -second span with an average pulse voltage of $600 \mathrm{~V}[1,2]$. Ophthalmic and orbital injuries from the TASER are mechanical (from the dart impalement and penetration of the heavier and larger portion of the probe) and electrical (thermal damage from the high energy current). TASER injuries to the globe and orbit often result in severe globe disfigurement and destruction of tissue that precludes globe-sparing surgery. Rafailov et al. [3] reported the first case of an impaled TASER probe globe/orbit penetration injury that required primary enucleation due to significant intraocular tissue necrosis and iatrogenic injury after extraction of the probe. The specific details of the globe injury and reasoning for primary enucleation were not discussed in their report.

It is known, among ophthalmologists, that evisceration has better functional and cosmetic outcomes than enucleation, and the incidence of sympathetic ophthalmia (SO) in traumatic open globes is exceedingly rare [4]. In light of this, we present a case similar to the case published by Rafailov et al. [3] in which we chose evisceration rather than enucleation. This case report adhered to the tenets of the Declaration of Helsinki and was compliant with the Health Insurance Portability and Accountability Act of 1996.

\section{Case Presentation}

A 34-year-old male presented to the emergency department after being subdued by police with a TASER gun. On examination, the patient had a TASER electrode penetrating his left globe and orbit (Fig. 1). Visual acuity was 20/20 in the right eye and no light perception in the left eye. There was marked diffuse hemorrhagic chemosis of the left globe with significant proptosis and prolapse of charred, coagulated uveal tissue consistent with reports that electrical discharge of the TASER probe occurred. Fundus examination was unable to be performed in the left eye due to the extent of the injury. Orbital imaging (computed tomography) demonstrates a cylindrical metallic foreign body that penetrated the globe and lodged in the left medial wall of the orbit (Fig. 2). 
Fig. 2. TASER probe following extraction. TASER, Thomas A Swift's Electric Rifle.

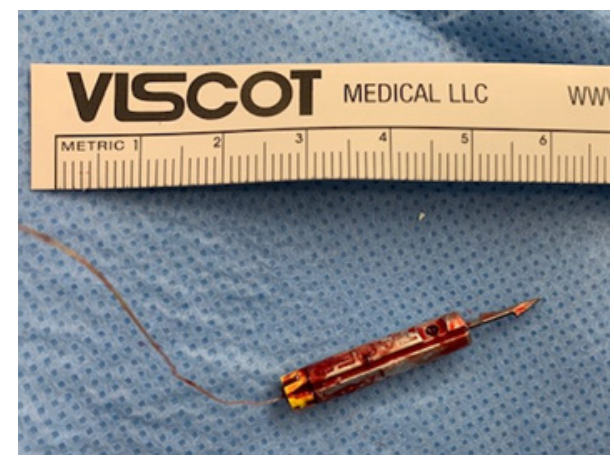

Fig. 3. The patient reported that he is satisfied with the cosmetic outcome of his surgery.

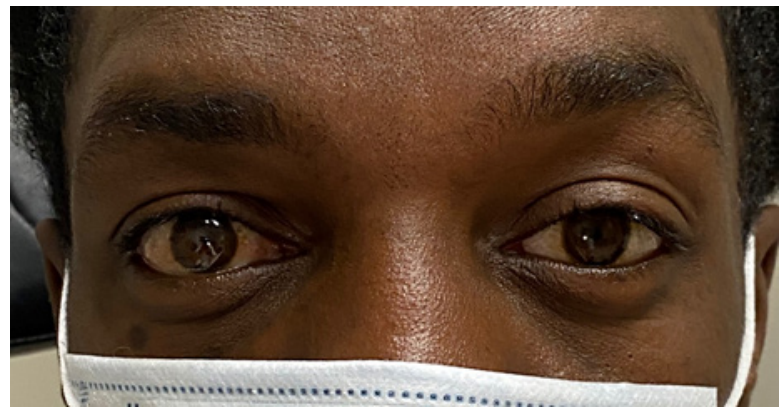

After receiving intravenous levofloxacin for endophthalmitis prophylaxis, the patient was taken to the operating room for exploration and extraction of the TASER probe (Fig. 3) with intentions of performing primary globe repair. However, a considerable amount of the intraocular contents including the uveal tissue, vitreous, and retina were found to be charred and tightly adherent to the probe or had already prolapsed through the corneal laceration. As a result, much of the intraocular contents was inevitably eviscerated upon extraction of the probe from the globe and orbit. Significant bleeding was encountered upon extraction of the probe, and bipolar cautery of the central retinal vasculature was necessary to achieve hemostasis. Given the degree of uveal tissue that was euthanized as well as the relative preservation of the scleral shell, the decision was made to perform a primary evisceration and placement of a porous polyethylene 22-mm sphere implant. Absolute alcohol was instilled to denature and remove all remaining uveal material and microorganisms from the scleral shell, thus mitigating the theoretical risk of sympathetic ophthalmia from remnant uveal pigment and minimizing infection risk. At a 6-month follow-up visit, the patient reported no issues with the uninjured eye and no socket pain on the left. Exam of the socket revealed healthy conjunctiva with no implant extrusion and good motility, and the patient reported that he is satisfied with the cosmesis, comfort, and movement of his prosthesis.

\section{Discussion}

Although deemed a less-than-lethal weapon, TASER electroshock weapons are capable of causing devastating injuries to facial and intraocular structures. The mechanical force of metal darts entering the orbit at $160 \mathrm{ft} / \mathrm{s}$ combined with an average pulse voltage of 600-700 V often results in globe disfigurement and destruction of tissue that portends a dismal visual outcome, and precludes globe sparing measures in many cases $[1,2]$. The 
9-13-mm-long darts are barbed and can damage the delicate superficial structures of the head and neck during both deployment and subsequent removal along the entry tract. Ocular tissues including the optic nerve and retina have a low resistance to electrical current; thus, they are prone to ischemia from coagulation and necrosis of their vascular supply [5]. It has been estimated that TASER darts strike and penetrate the face in $1 \%$ of cases, with even fewer cases of damage to the eye and orbit [6]. Several reports from 2005 onward describe mechanical and electrical injuries resulting in retinal detachment after anterior orbit perforation, cataract formation after electrical discharge across the eye, and globe perforation with uveal prolapse. The degree of injury attributed to electrical discharge in several reported cases, particularly in those with nonpenetrating injuries, has been disputed by some authors [1, 6-9]. A systematic review by Kroll et al. [9] demonstrated that among 28 cases of ocular TASER probe injuries, 12 cases resulted in enucleation and 6 other cases resulted in complete blindness.

When faced with a severely disfigured eye with no light perception after a penetrating TASER probe injury, the surgeon is often faced with the dilemma of offering the patient enucleation versus evisceration. Historically, the risk of SO affecting vision in the unaffected eye led surgeons to perform enucleation after catastrophic penetrating injury within 14 days of the injury. The incidences of SO following intraocular surgery and open globe trauma have been reported at $0.02 \%$ and $0.1-0.3 \%$ [10]. Using Bellan hypothetical calculations, Savar et al. [11] found that to prevent 1 incidence of blindness from SO, between 908 and 9,999 prophylactic enucleations are needed to be performed. These statistics reaffirm the thought that the injured eye should be salvaged and repaired with monitoring for SO with routine ophthalmic care. As a result, the practice of prophylactic enucleation to prevent SO in a traumatized eye has progressively fallen out of favor, as suggested by multiple case series discussing enucleation in traumatized eyes from other mechanisms $[12,13]$.

In cases in which primary repair is not possible due to severe disruption of the globe even with multifaceted injury patterns caused by TASER probes - the surgeon should avoid overlooking the option of primary evisceration for the patient. The advantages of evisceration include less disruption of the orbital anatomy, potentially better motility which results in superior functional and cosmetic outcomes, and lower rates of implant migration, extrusion, and conjunctival erosion than enucleation [4]. Despite Green's [14] 1972 report of 4 alleged cases of sympathetic ophthalmia following evisceration, our critical review of the literature shows that SO rarely occurs if ever following evisceration [15]. In our patient, despite the TASER barb penetrating through both the anterior and posterior globe with impalement into the medial orbital wall in addition to thermal and electrical injury to the intraocular structures, care was taken to preserve the integrity of the scleral shell during removal of the barb, allowing for successful primary evisceration.

\section{Conclusion}

We believe, after reviewing the literature discussed in this case report, that sympathetic ophthalmia is not an overwhelming indication to choose enucleation over evisceration in managing patients with catastrophic unsalvageable ocular injuries and that evisceration has an advantage over enucleation with regard to functional/cosmetic outcomes.

\section{Acknowledgments}

The authors would like to thank the patient for his consent to the publication of this case.

\section{Karger 'ह}


Sharabura et al.: Ocular TASER Probe Injury

\section{Statement of Ethics}

Written informed consent was obtained from the patient for publication of the details of his medical case and accompanying images. This case report adhered to the tenets of the Declaration of Helsinki and was compliant with the Health Insurance Portability and Accountability Act of 1996. This manuscript does not meet the definition of Human Subject Research at our institution, and the need for approval was waived by the Institutional Review Board.

\section{Conflict of Interest Statement}

The authors have no conflicts of interest to declare.

\section{Funding Sources}

No funding was received for this research or publication.

\section{Author Contributions}

Anna B. Sharabura contributed to the writing and reviewing of the manuscript. Joseph W. Fong contributed to the conceptualization, writing, and reviewing of the manuscript. Anna B. Sharabura and Joseph W. Fong agree to shared co-first authorship of this manuscript. John D. Pemberton contributed to the conceptualization and reviewing of the manuscript. All the authors agree to be accountable for all aspects of the work.

\section{Data Availability Statement}

All data generated or analyzed during this study are included in this article. Further inquiries can be directed to the corresponding author.

\section{References}

1 Sayegh RR, Madsen KA, Adler JD, Johnson MA, Mathews MK. Diffuse retinal injury from a non-penetrating TASER dart. Doc Ophthalmol. 2011;123(2):135-9.

2 Dawes DM, Ho JD, Kroll MW, Miner JR. Electrical characteristics of an electronic control device under a physiologic load: a brief report. Pacing Clin Electrophysiol. 2010;33:330-6.

3 Rafailov L, Temnogorod J, Tsai FF, Shinder R. Impaled orbital TASER probe injury requiring primary enucleation. Ophthalmic Plast Reconstr Surg. 2017;33(3S Suppl 1):S176-7.

4 Nakra T, Simon GJ, Douglas RS, Schwarcz RM, McCann JD, Goldberg RA. Comparing outcomes of enucleation and evisceration. Ophthalmology. 2006 Dec;113(12):2270-5. Epub 2006 Sep 25.

5 Grover S, Goodwin J. Lightning and electrical injuries: neuroophthalmologic aspects. Semin Neurol. 1995;15: 335-41.

6 Li JY, Hamill MB. Catastrophic globe disruption as a result of a TASER injury. J Emerg Med. 2013;44(1):65-7.

7 Seth RK, Abedi G, Daccache AJ, Tsai JC. Cataract secondary to electrical shock from a Taser gun. J Cataract Refract Surg. 2007 Sep;33(9):1664-5.

8 Chen SL, Richard CK, Murthy RC, Lauer AK. Perforating ocular injury by Taser. Clin Exp Ophthalmol. 2006 May-Jun;34(4):378-80.

9 Kroll MW, Ritter MB, Kennedy EA, Silverman NK, Shinder R, Brave MA, et al. Eye injuries from electrical weapon probes: incidents, prevalence, and legal implications. J Forensic Leg Med. 2018 Apr;55:52-7. Epub 2018 Feb 14. 


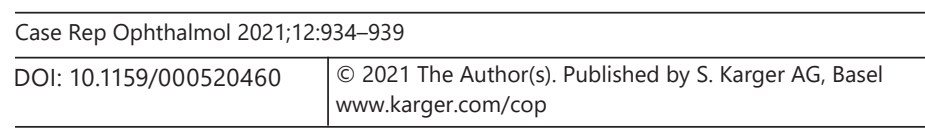

Sharabura et al.: Ocular TASER Probe Injury

10 Migliori ME. Enucleation versus evisceration. Curr Opin Ophthalmol. 2002;13(5):298-302.

11 Savar A, Andreoli MT, Kloek CE, Andreoli CM. Enucleation for open globe injury. Am J Ophthalmol. 2009;147: 595-600.e1.

12 Reed D, Papp A, Brundridge W, Mehta A, Santamaria J, Valentin F, et al. Evisceration versus enucleation following ocular trauma, a retrospective analysis at a level one trauma center. Mil Med. 2020 Mar 2;185(3-4): 409-12.

13 Holmes CJ, McLaughlin A, Farooq T, Awad J, Murray A, Scott R. Outcomes of ocular evisceration and enucleation in the British Armed Forces from Iraq and Afghanistan. Eye. 2019 Nov;33(11):1748-55. Epub 2019 Jun 5 .

14 Green WR, Maumenee AE, Sanders TE, Smith ME. Sympathetic uveitis following evisceration. Trans Am Acad Ophthalmol Otolaryngol. 1972;76:625-44.

15 Phan LT, Hwang TN, McCulley TJ. Evisceration in the modern age. Middle East Afr J Ophthalmol. 2012 Jan; 19(1):24-33. 